\title{
Recovery of fibers and biomethane from banana peduncles biomass through anaerobic digestion
}

\author{
Florent Awedem Wobiwo' ${ }^{1,2,4}$, Virginie Korangi Alleluya ${ }^{1}$, Thomas Happi Emaga ${ }^{3}$, Maurice Boda ${ }^{4}$, \\ Elie Fokou ${ }^{2}$, Sebastien Gillet ${ }^{5}$, Magali Deleu ${ }^{6}$, Aurore Richel ${ }^{5}$ and Patrick A. Gerin ${ }^{1 *}$ \\ ${ }^{1}$ Laboratory of Bioengineering, Earth and Life Institute - Université Catholique de Louvain, Croix du Sud, 2 - L7.05.19, B-1348 \\ Louvain-la-Neuve, Belgium. \\ ${ }^{2}$ Laboratory for Food Science and Metabolism, Department of Biochemistry, University of Yaoundé I, P. O. Box 812 Yaoundé, \\ Cameroon. \\ ${ }^{3}$ Post harvest Technology Laboratory, African Research Centre on Bananas and Plantains (CARBAP), Njombé, P. O. Box 832 \\ Douala, Cameroon. \\ ${ }^{4}$ Laboratory of Microbiology, Department of Microbiology, University of Yaoundé I, P. O. Box 812 Yaoundé, Cameroon. \\ ${ }^{5}$ Unit of Biological and Industrial Chemistry, ${ }^{6}$ Laboratory of Molecular Biophysics at Interfaces, Gembloux Agro-Bio Tech, \\ Passage des Déportés 2, B-5030 Gembloux, Belgium. \\ *Corresponding Author's address: E-mail: patrick.gerin@uclouvain.be
}

Banana crop produces large quantities of post-harvest biomass wastes that can be valorized as a renewable source of raw materials or bioenergy. However, their lignocellulosic nature and high water content prevent a broader use. They can be a potential source of natural biodegradable fibers, which can be used in papers and textile, and as reinforcement in the manufacture of several composite materials for aeronautics and cars. For this purpose, sustainable fiber extraction and isolation techniques need to be developed. In this study, we tested the conversion of soft peduncles tissues from three banana varieties to biogas and assessed the yield of recovery of the less digestible fibers. The process was found to be effective as a method for fiber extraction from banana peduncles. The amount and the quality of recovered fiber strongly depended both on the duration of anaerobic digestion and the banana variety. The tested cooking banana variety allowed the recovery of a significant amount of fibers while the soft tissues were converted to biomethane. The optimum digestion time for fibers and biogas recovery was identified as about 40 days, with yields of 0.2 ton_dry_fiber/ha/year and $349 \mathrm{~m}^{3} \_\mathrm{CH} 4 / \mathrm{ha} /$ year. These natural fibers have attractive technical, economic and environmental advantages. Dessert banana varieties were found to be more convenient for the biomethane production, as fiber degraded in less than 20 days of digestion time, and the total methane produced annually from banana peduncles ranged from 200 to $204 \mathrm{~m}^{3} /$ ha/year. These results confirm that banana peduncles biomass can be considered as a source of renewable raw materials and energy in developing countries like Cameroon.

Keywords: Anaerobic digestion, Banana peduncle, Fibers, Biomethane, Grande naine, Pelipita, CRBP 969 variety.

\section{2-13/05/2016, Gembloux : International conferences "Green chemistry and White biotechnology".}

